RESULTS

Figure 1 presents the probability of correct recall on the initial test as a function of study method, cue, and lists. Imagery rather than repetition resulted in superior recall $[F(1,19)=181.4, p<.001]$. Recall improved over lists $[F(2,34)=5.83$, $p<.01]$, although there was no difference between recall performance on Lists 2 and 3 $(F<1)$. Cueing enhanced recall of List 1 items $[F(1,17)=7.62, p<.025]$, but the direction of the effect was slightly reversed thereafter, resulting in a Cue Condition by List interaction $[F(2,34)=3.61, p<.05]$. No other sources of variance were significant.

Since $97.6 \%$ of the correct responses in the retest were also correct in the initial test, the measure of retention used for analysis was the proportion of items correctly recalled in the initial test that were correctly recalled 1 week later. Preliminary analyses revealed that cue condition in retest did not influence recall $(F<1)$, and the retest scores were accordingly pooled over cue condition in order to provide more reliable data. Table 1 presents the retention percent. ages, averaged over $\mathrm{Ss}$, for each combination of study method and lists. Retention was better for I items than for $R$ items $[F(1,17)=10.46, p<.005]$. For both study methods, List 1 retention was better than retention of Lists 2 and 3 , although this difference was significant only for litems $[F(2,34)=5.15, \mathrm{p}<.025]$.

\section{DISCUSSION}

The result that noun pairs studied by imagery are better learned and better remembered than items studied by repetition replicates the findings of previous research in which study method was varied between Ss (Paivio \& Yuille, 1967; Yuille \& Paivio, 1968). Since the present experiment manipulated study method within $\mathrm{Ss}$, it is apparent that $S s$ are able to employ two different encoding strategies concurrently during the presentation of a single list.

The hypothesis that different memory stores are associated with the two study methods is supported by the finding that knowledge of study method aided recall of List 1 items. The enhanced recall implies that retrieval-relevant information increased the probability that $S$ would search the appropriate memory store during test, thereby decreasing interference effects between I items and R items. The absence of a cue effect for Lists 2 and 3 suggests that stimulus information alone was employed during recall of these lists. Since a refinement in storage processes could have resulted in stimulus information alone directing $S$ to the appropriate memory store during test, the lack of a cue effect for Lists 2 and 3 is not necessarily in opposition to a dual-storage hypothesis.
Table I

Probability of Correct Retest Recall Given Correct Recall on the Initial Test

\begin{tabular}{lccc}
\hline & \multicolumn{3}{c}{ List Order } \\
\cline { 2 - 5 } Study Method & 1 & 2 & 3 \\
\hline Imagery & .453 & .341 & .352 \\
Repetition & .311 & .239 & .247 \\
\hline
\end{tabular}

The surprising result was that list-order effects for initial and delayed recall scores were opposite in direction. Relative to performance on Lists 2 and 3, initial recall was poorer; however, recall a week later was superior for List 1 items. This seemingly anomalous relationship implies that the storage process operative during List 1 study differed from that employed during the study of subsequent lists. One possible hypothesis is as follows: Prior to test experience $S$ was not aware of the studytest interval and, to insure a high level of performance, studied List 1 items so that they would be remembered over very long retention intervals. After the test on List 1, this storage process (SP-1) was replaced by one more appropriate to the study-test interval actually employed on the first day (SP-2). In order to account for the data, it must be assumed that SP-1 produced more interitem interference than did SP-2, with the result that: (1) initial recall performance was lower for List 1 items than for items in Lists 2 and 3, and (2) providing retrievalrelevant information during List 1 test enhanced recall.

\section{REFERENCES}

ATKINSON, R. C., \& SHIFFRIN, R. M. Human memory: A porposed system and its control processes. In K. W. Spence and J. T. Spence (Eds.), The psychology of learming and motivation: Advances in research and theory. Vol. 2. New York: Academic Press, 1968. Pp. 89-195.

HOWES, D. A word count of spoken English. Journal of Verbal Leaming \& Verbal Behavior, $1966,5,572-604$.

PAIVIO, A., \& YUILLE, J. C. Mediation instructions and word attributes in pairedassociate learning. Psychonomic Science, 1967, 8, 65-66.

PAIVIO, A., YUILLE, J. C., \& MADIGAN, S. A. Concreteness, imagery, and meaningfulness values for 925 nouns. Journal of Experimental Psychology, 1968, 76, No. 1, Part 2, 1-25.

YUILLE, J. C., \& PAIVIO, A. Imagery and verbal mediation instructions in paired-associate learning. Journal of Experimental Psy chology, 1968, $78,436-441$.

\section{NOTES}

1. This research was conducted during the senior author's tenure as a Public Health Service Postdoctoral Fellow at Stanford University.

2. While the selection criterion was subjective, the words used in this study that are in the Paivio, Yuille, \& Madigan (1968) norms $(N=54)$ have concreteness and imagery values greater than 6.0 .

\title{
Facilitation of paired-assoclate learning by language context
}

MARK WIND and MICHAEL DAVIDSON, University of Rochester, Rochester, N.Y. 14627

Subjects learned associations between English words and unfamiliar items (CVC syllables). Control Ss used a traditional paired-associate method; experimental $S$ s received each pair in a sentence context appropriate for the English word. Learning was facilitated by the language context.

The learning of a second-language vocabulary may be viewed in part as paired-associate learning of first- and second-language synonyms (e.g., tree-Baum in English-German vocabulary). Mediational theories of meaning (Osgood, 1953) suggest that such learning could be facilitated by evoking a context of inplicit meaning responses for the familiar word when the pair is presented. One appropriate method might be to provide a sentence context for the familiar word during training, as in "The $B A U M$ had beautiful autumn leaves (TREE)." Naive association theory, on the other hand, might suggest that the additional context items would interfere with the association to be formed. Our experimental question is whether paired. associate learning between an English word and an unfamiliar item is enhanced by providing a meaningful-sentence context for the English word.

\section{SUBJECTS}

The Ss were 64 students in an introductory psychology course at the University of Rochester. Participation in experiments was a course requirement. 


\section{DESIGN}

Eight groups of eight $\mathrm{Ss}$ each were defined by three experimental factors: (1) Half the Ss received a sentence context for each English word during training; the other half was given simple paired-associate training. (2) Half the Ss in each training condition were given a context test followed by a simple paired-associate test; the other half were given the tests in the reverse order. (3) Two different sets of word-syllable pairs were given, each to half the Ss.

\section{PROCEDURE}

The Ss were tested in groups of 16. The task was essentially to learn 10 pairs, each an English word and a CVC syllable. Each of three leaming trials was conducted as follows: The 10 pairs were projected onto a screen for $20 \mathrm{sec}$; Ss were instructed to learn the associations. Context-learning Ss saw 10 sentences containing a CVC syllable, with the corresponding words in parentheses after the sentences, e.g., "What time is BAP served? (DINNER)." Paired-associatelearning Ss saw only the 10 syllable-word pairs, e.g., "BAP DINNER." Then all Ss were given $60 \mathrm{sec}$ to complete a response sheet, consisting of 10 sentences such as "BAP is a word that means_." The Ss were, of course, to recall the English word, the correct response for this example being "DINNER." The order of the 10 items on the response sheet was different from that projected on the screen, and the order was varied from trial to trial, both in the projected stimulus and on the response sheets.

After the third learning trial, Ss were given two tests. The paired-associate test consisted of the English words as stimuli, to which $\mathrm{S}$ gave a $\mathrm{CVC}$ syllable as response. The context test was a paragraph with 10 blanks such as that given by Manis $(1966$, p. 68). The words omitted were those used in the learning phase, and the context was redundant, in the sense that the English words could be easily determined from the context. The Ss' task was to fill the blanks with the appropriate CVC syllables. For both tests, the list of $10 \mathrm{CVC}$ syllables appeared at the bottom of the page; this reduced the problem of response learning in the test, and made the task one more of recognition than of recall. Note that the tests reflect backwards learning since the syllable is now the response. As indicated above, the order of the two tests was varied between Ss.

\section{ITEMS}

The $20 \mathrm{CVC}$ syllables have Noble associative values (Noble, 1961) between 0.84 and 0.86 . The 20 English words were selected randomly from the 60 highest. meaningfulness words in Noble's list (Noble, 1952). The pairs were formed randomly, and 10 given to each $S$.

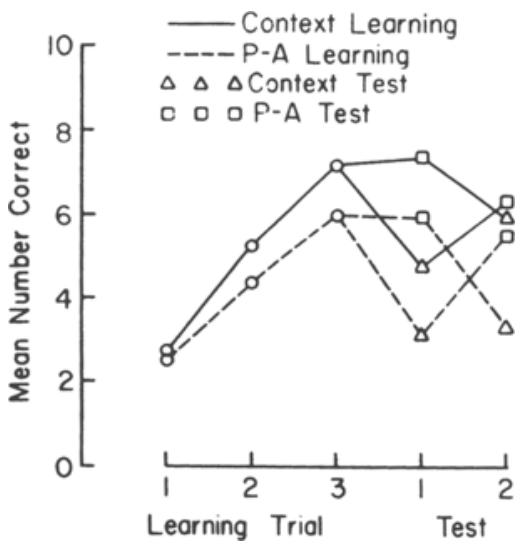

Fig. 1. Correct responses over learning and test trials.

\section{RESULTS}

The mean number of correct responses for the various trials is shown in Fig. 1. The differences indicated on the first test are statistically significant: the paired-associate test is easier than the context-paragraph test $(F=18.9, \mathrm{df}=1,56, \mathrm{p}<0.01)$, and the context-learning method is superior to the paired-associate me thod $(\mathrm{F}=6.0, \mathrm{df}=1,56$, $\mathrm{p}<0.05)$. There is no interaction between training and test methods, as might have been expected from a transfer-of-training argument. The only difference retaining significance on the second test is that the context-learning method is superior to the paired-associate method $(F=6.8, d f=1,56$, $\mathrm{p}<0.05$ )

Analysis of the changes from the first to the second test (which is statistically redundant with the analyses just reported) also confirms the impression given by Fig. 1 . The change is a strong function of which test was given first $(F=95.4, d f=1,56$, $\mathrm{p}<0.01$ ), and there is some interaction between learning condition and which test was given first $(\mathrm{F}=6.0, \mathrm{df}=1,56$, $\mathrm{p}<0.05)$. There are no other significant differences between the first and second tests.

There are no differences of any kind between the two lists of pairs.

\section{DISCUSSION}

The context-paragraph test may have been inferior to the paired-associate test simply because the English words were not seen easily enough in the blanks of the paragraph presented. It seemed important to include tests as similar as possible to each learning condition because of the possibility of transfer-of-training effects, but in view of the results the context-test data are of minor importance. Testing backwards learning was made necessary by the inclusion of the context-paragraph test; a backwards. learning test seems acceptable since (1) backwards and forwards learning are probably equivalent when the responselearning phase of paired-associate learning is minimized [e.g., Horowitz, Brown, \& Weissbluth (1964)], and (2) response. learning was not important in this experiment since the responses were listed on the response sheets.

Our major result is that the learning of associations between English words and unfamiliar items is facilitated by providing a language context for the English words. This has obvious practical implications for the training of second-language vocabulary. A number of observations may be made with regard to possible processes involved. First, Ss are accustomed to learning the meaning of new English words through seeing them used in a language context. With this in mind, it would be interesting to compare context learning such as used here with definition learning, as in "BAP is the largest meal of the day, usually served in the evening." Second, presence of context during learning may serve in part to make $S s$ more active in their reception of the material, facilitating learning.

The supposed mediational responses given by the context may, of course, be of many kinds. There are syntactic cues; the sentence, "What time is BAP served?" fixes BAP as a noun or pronoun. The context sentences, like most of English, are semantically redundant to some extent. Redundancy is known to aid both speech perception (Miller, Heise, \& Lichter, 1951) and comprehension (Taylor, 1953), imply. ing that our unfamiliar item appears contiguously with many relevant implicit responses given by the language. comprehension processes. It is probable that some mechanism of this general kind is responsible for the results observed.

\section{REFERENCES}

HOROWITZ, L. M., BROWN, Z. M., \& WEISSBLUTH, S. Availability and the direction of associations. Journal of Experimental Psychology, 1964, 68,541-549.

MANIS, M. Cognitive processes. Belmont, Calif Wadsworth Publishing Co., 1966.

MILLER, G. A., HEISE, G. A., \& LICHTER, W The intelligibility of speech as a function of the context of the test materials. Joumal of Experimental Psychology, 1951, 41, 329-335.

Ni)BLE, C. E. Measurement of associative value (a), rated associations $\left(a^{\prime}\right)$ and scaled meaningfuhess $\left(\mathrm{m}^{\prime}\right)$ for the $2100 \mathrm{CVC}$ combinations of the English alphabet. Psychological Reports, 1961, 8, 487-521.

NOBLE, C. E. An analysis of meaning. Psychological Review, 1952,59,421-430.

OSGOOD, C. E. Method and theory in experimental psychology. New York: Oxford University Press, 1953.

TAYLOR, W. L. "Cloze procedure": A new tool for measuring readability. Joumalism Quarterly, $1953,30,415-433$

\section{NOTE}

1. We are grateful to Frank Dapolito for helpful comments on the design of this experiment. 